\title{
COMPOSIÇÃO FLORÍSTICA E ESTRUTURA DE DOSSEL EM TRECHO DE FLORESTA OMBRÓFILA DENSA ATLÂNTICA SOBRE MORROTE mamelonar na Reserva Biológica de Poço das Antas, Silva Jardim, Rio de JANEIRo, BrasiL ${ }^{1}$
}

\author{
Rejan R. Guedes-Bruni², Sebastião José da Silva Neto, \\ Marli P. Morim ${ }^{2} \&$ Waldir Mantovani ${ }^{4}$
}

\section{Resumo}

(Florística e estrutura de dossel em floresta sobre morrote mamelonar no Rio de Janeiro, Brasil) Os remanescentes de Floresta Ombrófila Densa submontana Atlântica, ocorrentes nos mamelões da baixada do Rio de Janeiro, carecem de estudos florísticos e estruturais. Inventariou-se $1 \mathrm{ha}$, empregando parcelas, adotando como critério de inclusão DAP $\geq 5 \mathrm{~cm}$ e, através de relações alométricas, estabeleceu-se como árvores de dossel aquelas com limites de DAPs e alturas superiores a $10 \mathrm{~cm}$ e $10 \mathrm{~m}$, respectivamente. Foram amostrados 580 indivíduos, de 174 espécies e 45 famílias. O índice de diversidade de Shannon ( $\mathrm{H}^{\prime}$ ) foi de 4,57 nats/ind e a eqüabilidade (J) de 0,88 , valores próximos aos encontrados para a Floresta Ombrófila Densa submontana Atlântica no estado. Dentre as famílias com maiores riquezas, reunindo ca. 74\% das espécies destacam-se: Euphorbiaceae, Fabaceae, Moraceae, Lauraceae, Melastomataceae, Myrtaceae, Monimiaceae, Clethraceae, Flacourtiaceae, Annonaceae, Rubiaceae, Meliaceae, Sapindaceae e Myristicaceae. Destacam-se como espécies com maiores VIs: Senefeldera verticillata, Siparuna reginae, Mabea piriri, Casearia sylvestris, Clethra scabra, Tibouchina scrobiculata, Pseudopiptadenia inaequalis, Guapira opposita, Apuleia leiocarpa e Brosimum guianense. Caracterizam-se como espécies indicadoras de morrote: Apuleia leiocarpa, Eugenia macahensis, Simarouba amara e Pseudopiptadenia contorta. Palavras-chave: Mata Atlântica, florística, estrutura de comunidade, dossel, floresta de baixada, mamelões.

\section{Abstract}

(Floristics and structure of the forest canopy on hillocks in the lowlands, Rio de Janeiro, Brazil) The remnant areas of Atlantic coastal Forest on hillocks in the coastal lowlands of Rio de Janeiro State, Brazil, have been poorly studied in terms of both their structure and floristics. Sample plots, totaling one hectare, were inventoried using a DBH $\geq 5 \mathrm{~cm}$ inclusion criterion. Allometric relationships were used to define a canopy tree as having a DBH $\geq 10 \mathrm{~cm}$ and height $\geq 10 \mathrm{~m}$. A total of 580 individuals were sampled, comprising 174 species belonging to 45 families. The Shannon diversity index $\left(\mathrm{H}^{\prime}\right)$ was 4.57 nats/ind, and the equitability $(\mathrm{J})$ was 0.88 . These were considered representative values for an area of Atlantic Coastal Forest in that state. Among the families with the highest species richness (74\% of the total number of species) were: Euphorbiaceae, Fabaceae, Moraceae, Lauraceae, Melastomataceae, Myrtaceae, Monimiaceae, Clethraceae, Flacourtiaceae, Annonaceae, Rubiaceae, Meliaceae, Sapindaceae, and Myristicaceae. Among the species with the highest VI were: Senefeldera verticillata, Siparuna reginae, Mabea piriri, Casearia sylvestris, Clethra scabra, Tibouchina scrobiculata, Pseudopiptadenia inaequalis, Guapira opposita, Apuleia leiocarpa, and Brosimum guianense. The indicator species for hillock forests were: Apuleia leiocarpa, Eugenia macahensis, Simarouba amara, and Pseudopiptadenia contorta. Key words: Atlantic Coastal Forest, floristics, community structure, canopy, lowland forest, hillocks.

\section{INTRODUÇÃO}

A análise do estado de conservação da Floresta Ombrófila Densa Atlântica, especialmente no Rio de Janeiro, reduzida hoje a aproximadamente $16,73 \%$ do território do estado, limita-se a pequenas áreas particulares ou a unidades de conservação. Apenas $29,8 \%$, do total de remanescentes no Rio de Janeiro, encontram-se circunscritos a Unidades de Conservação (Fundação SOS Mata Atlântica/

Artigo recebido em 09/2005. Aceito para publicação em 10/2006.

${ }^{1}$ Parte da tese de doutorado da primeira autora, apresentada ao Depto. Ecologia - USP.

${ }^{2}$ Programa Mata Atlântica, Jardim Botânico do Rio de Janeiro.

${ }^{3}$ Fundação Botânica Margaret Mee/ Programa Mata Atlântica, Jardim Botânico do Rio de Janeiro.

${ }^{4}$ Depto. Ecologia, Instituto de Biociências, Universidade de São Paulo - USP/ bolsista CNPq. Apoio financeiro: Petrobras/ Jardim Botânico do Rio de Janeiro/MMA.

Autor para correspondência: Rejan R.Guedes-Bruni. Jardim Botânico do Rio de Janeiro. Programa Mata Atlântica. Rua Pacheco Leão 915, 22460-020, Rio de Janeiro, RJ. rbruni@jbrj.gov.br 
INPE 2002). A relevância de estudos nestes remanescentes, sob mesmo domínio fitogeográfico, porém muito distintos entre si resultantes do processo, de décadas, de fragmentação florestal, a partir de usos diferenciados do solo - já foi destacada por Guedes-Bruni et al. (2006), ao tratar de trecho de mata aluvial na Reserva Biológica de Poço das Antas.

Um dos componentes mais típicos da paisagem da Baixada Fluminense, observado de forma patente a partir do alto das serranias, são os chamados morros mamelonares ou mamelões, que não ultrapassam $300 \mathrm{~m}$ de altitude, sustentados por rochas do cristalino, afogados nos depósitos flúvio marinhos litorâneos e designados por "mar de morros".

As florestas aluviais que os circundam devido à ocorrência sobre terrenos planos, ainda que brejosos, facilitaram o estabelecimento de residências e atividades agrícolas - foram impactadas em períodos anteriores, desde a implantação da agromanufatura do açúcar, a partir do séc. XVI, até mais recentemente no séc. XX, a partir da década de 30 com a expansão das áreas rurais (Lamego 1940, 1946 e 1948 ; Golfari \& Moosmayer 1980; Azevedo 1996) e cujas matas que revestem estes morrotes, são, em sua maioria, remanescentes alterados da vegetação nativa da região, anterior aos processos de antropização das áreas de baixada do estado do Rio de Janeiro. Nestes mamelões, ora totalmente desnudos, ora cobertos por florestas - designadas popularmente como matas de baixada - com diferentes dimensões e em diversos estádios sucessionais, é a pecuária a ação antrópica mais evidente e, em decorrência dela, o fogo o precursor da sua alteração e um dos determinantes principais no estabelecimento das espécies.

Inúmeros estudos mais recentes sobre florestas submontanas, alguns desenvolvidos em regiões próximas à Reserva Biológica de Poço das Antas, posteriores aos anos 80 do século passado, podem ser encontrados em Guedes-Bruni et al. (2006).
Objetiva-se neste estudo caracterizar florística e estruturalmente o dossel de um dos últimos remanescentesde floresta ombrófila densa submontana sobre morrotes no Rio de Janeiro, em avançado estado de conservação, salvaguardado em Unidade de Conservação (UC) - o que possibilitará, a partir de monitoramento, reavaliar o estado da floresta futuramente, à luz do reconhecimento ora feito e avaliar, com maior propriedade, os processos sucessionais que venham a ocorrer.

\section{Material e Métodos}

\section{Caracterização da área de estudo}

A despeito dos processos de erosão antrópica, as condições úmidas dominantes aparecem como responsáveis pelo modelamento de formas colinosas. A presença da formação Barreiras no litoral centro-norte do estado do Rio de Janeiro, cujos tabuleiros restringem-se à área de contato entre a baixada flúvio-marinha e a encosta, acaba por originar a baixada dos Goitacazes ou Baixada Fluminense, constituída por matéria argilosa e areno-argilosa, profundamente edafisadas e com concreções ferruginosas na superfície. As camadas de argila negra e turfas são indicativas dos avanços e recuos do mar (IBGE 1977).

Os trabalhos de Lamego (1940 e 1946) - que ao longo de sua obra conseguiu unir espaço, tempo e homem para compreensão sinérgica do ambiente - mostram as formações físicas das baixadas costeiras em direção ao interior do território, bem como os processos de formação sócioeconômica e as barreiras naturais (grandes extensões de areia, pântanos e brejos) - com o concurso da resistência indígena à ocupação do solo pelos europeus como fatores determinantes no arranjo paisagístico da região e na organização fisiográfica, não só desta área de interesse, como do estado do Rio de Janeiro. A análise minuciosa da obra deste engenheiro de formação, porém estudioso dedicado à geografia, revela não só sua extrema sensibilidade, como, sua surpreendente contemporaneidade. 
A área que constitui a Reserva Biológica de Poço das Antas (Rebio) foi, no passado, como em grande parte a baixada litorânea do Rio de Janeiro, explorada como área de lavoura e pastagem, e as manchas de floresta que sobreviveram à expansão agrícola ao norte do Rio de Janeiro são resultantes de processos sucessionais de diferentes épocas e distintos manejos de solos. A caracterização da Reserva, no que tange às características de área, solo, clima e vegetação encontra-se em Lima et al. (2006)

Sobre os morros mamelonares, sem a influência das cheias, estabelece-se a Floresta Ombrófila Densa submontana Atlântica, com estrutura heterogênea devido ao desenvolvimento dos solos e ao grau de conservação das áreas florestadas. Ao longo do texto serão tratadas, resumidamente, por mata de morrote ou floresta sobre morrote.

\section{Coleta de dados}

Foi selecionado um pequeno fragmento florestal na Rebio, com aproximadamente 4 ha de área, aí incluída uma lage exposta com ca. $25 \mathrm{~m}^{2}$. Foram alocadas, sistematicamente, alternadamente ao longo do eixo de aclive, 40 unidades amostrais de $10 \times 25 \mathrm{~m}$, dispostas em faixas com quatro unidades cada uma, totalizando 1 ha de área, num mesmo fragmento, sobre morrote mamelonar, a sudeste dos limites da área da Rebio, com altitude de $250 \mathrm{~m} . \mathrm{sm}$. e distanciadas em pelo menos 20 metros das trilhas ou lages, para a implantação do ponto inicial da parcela, buscando-se evitar, com isto, o efeito de borda.

A amostragem incluiu todos os indivíduos arbóreos e arborescentes (palmeiras e fetos arborescentes) com diâmetro do caule a 1,3 m do solo (DAP) igual ou superior a $5 \mathrm{~cm}$. Quando os indivíduos apresentavam caule ramificado, eram tomadas as medidas de todas as ramificações para posterior cálculo da área basal e DAP equivalente para aplicar o critério de inclusão. $\mathrm{O}$ material testemunho encontra-se depositado no herbário do Jardim Botânico do Rio de Janeiro (RB). Nas listas de espécies as morfo-espécies são relacionadas e, em várias ocasiões, em sequiência que gera estranhamento ao leitor, visto que não é seqüencial. Explicase: o material faz parte da coleção do Programa Mata Atlântica (PMA), onde muitas pesquisas são conduzidas simultâneamente. Objetivando a acurácia da informação taxonômica, todos os pesquisadores, adotam a identificação padronizada pelo PMA, de modo que até mesmo as morfo-espécies, sigam a mesma nomenclatura, razão pela qual são encontradas morfoespécies com números não seqüenciais (p.ex.: Guatteria sp.4), visto que em outras pesquisas do PMA foram identificadas as antecedentes (as quais não foram amostradas no presente estudo), que por sua vez se distinguem do exemplar coligido neste trabalho.

$\mathrm{Na}$ definição de dossel foram estabelecidas relações alométricas entre diâmetro e altura (fig.1), transformados pelo respectivo logaritmo decimal (Sneath \& Sokal 1973), para todos os indivíduos coletados nas diferentes áreas, identificando o dossel a partir da linha indentada evidenciada no diagrama de correlação. Com isto, foram fixados como elementos de dossel todos os indivíduos que apresentassem diâmetros iguais ou superiores a $10 \mathrm{~cm}$ e alturas iguais ou superiores a $10 \mathrm{~m}$, a partir da verificação da primeira descontinuidade entre os pontos.

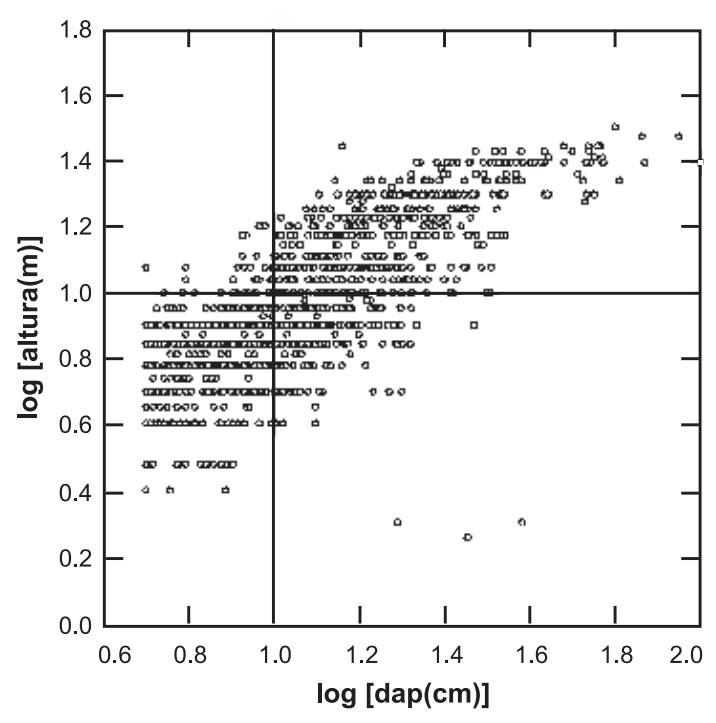

Figura 1 - Relação alométrica entre diâmetro e altura, dos indivíduos com DAP $\geq 5$, amostrados na floresta sobre morrote, para definição dos limites do dossel. 
O sistema fitogeográfico adotado na classificação da vegetação foi o de Veloso et al. (1991). O sistema de classificação taxonômica adotado segue Cronquist (1988), excetuandose Fabaceae, que foi considerada como família única, de acordo com Polhill et al. (1981).

\section{Processamento e análise dos dados}

$\mathrm{O}$ processamento dos dados da amostragem foi executado pelo programa FITOPAC (Shepherd 1995) para o qual foram calculados parâmetros tais como: densidade relativa (Dr), freqüência relativa ( $F r)$, dominância relativa (Dor) a partir da área basal, o volume cilíndrico obtido pela multiplicação da área basal pela altura total, e o valor de importância (VI). Para análise da diversidade florística adotou-se o Índice de Diversidade de Shannon (H') e de eqüabilidade (J') de acordo com Magurran (1988) e Pielou (1984) respectivamente, com a base logarítmica natural.

\section{Resultados e Discussão}

$\mathrm{Na}$ amostragem do dossel (DAP $\geq 10 \mathrm{~cm}$ ) foram coligidos 580 indivíduos, totalizando $26,85 \mathrm{~m}^{2} / \mathrm{ha}$ de área basal e $571,36 \mathrm{~m}^{3} \mathrm{de}$ volume/ ha.

Identificaram-se 174 espécies (tab. 1), de 45 famílias; o índice de diversidade de Shannon $\left(\mathrm{H}^{\prime}\right)$ foi de 4,57 nats/ind., enquanto a eqüabilidade (J) foi de 0,88 , valores comumente encontrados em estudos na Floresta Ombrófila Densa submontana e montana no Rio de Janeiro, conforme estudo de Guedes-Bruni (1998). As alterações ocorridas nas paisagens da Rebio, à primeira vista, induzem uma percepção de baixa riqueza e diversidade em suas florestas, no entanto, os processos sucessionais diferenciados que ocorrem simultaneamente, em escalas temporais, como respostas à interferência nos remanescentes, além da heterogeneidade de ambientes, principalmente no substrato, relacionado à formação mamelonar, acabam por gerar elevadas riqueza e diversidade de espécies.

Tabela 1 - Relação das espécies registradas na amostragem da Floresta Ombrófila Densa submontana sobre morrote na Reserva Biológica de Poço das Antas.

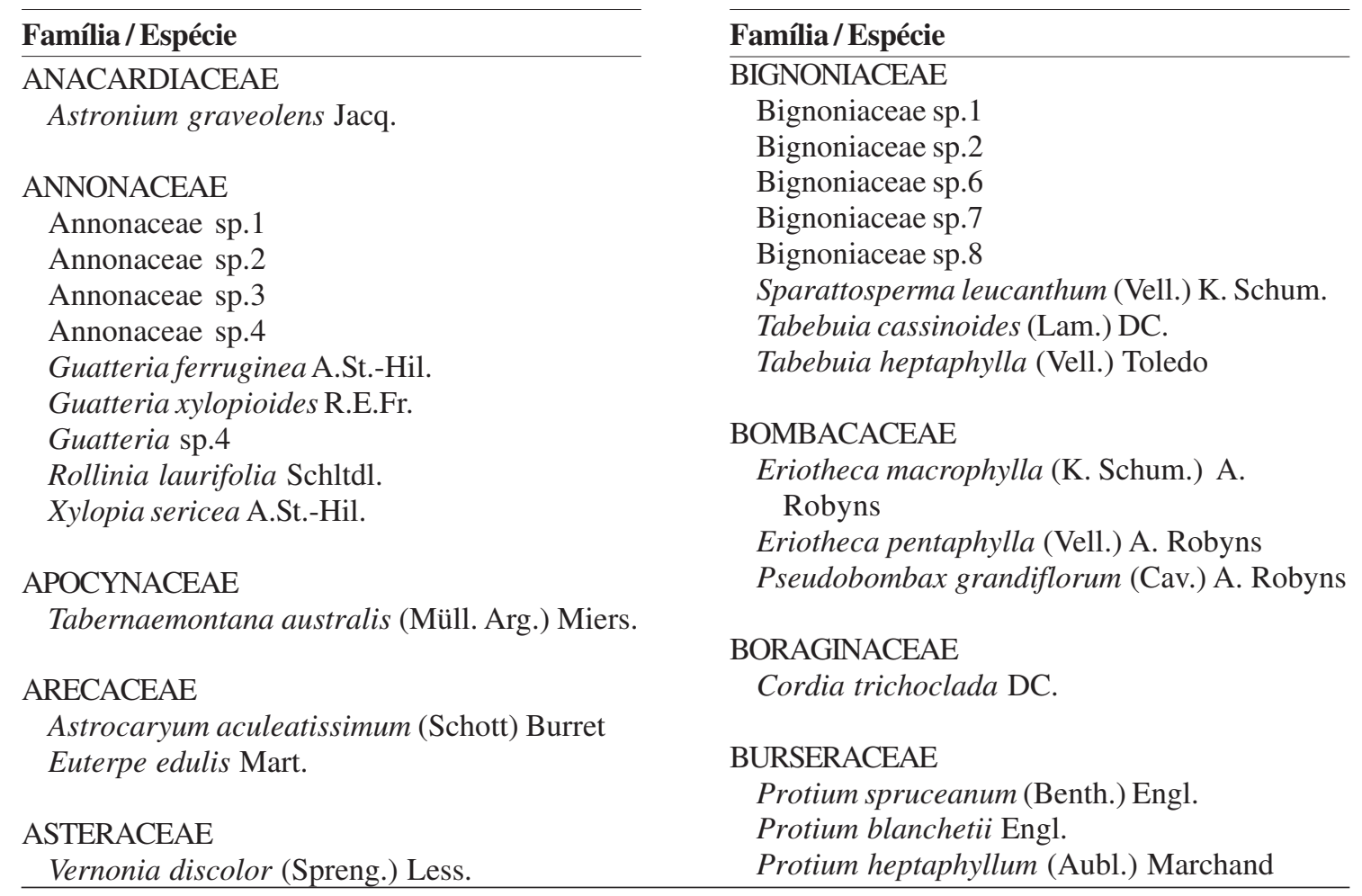




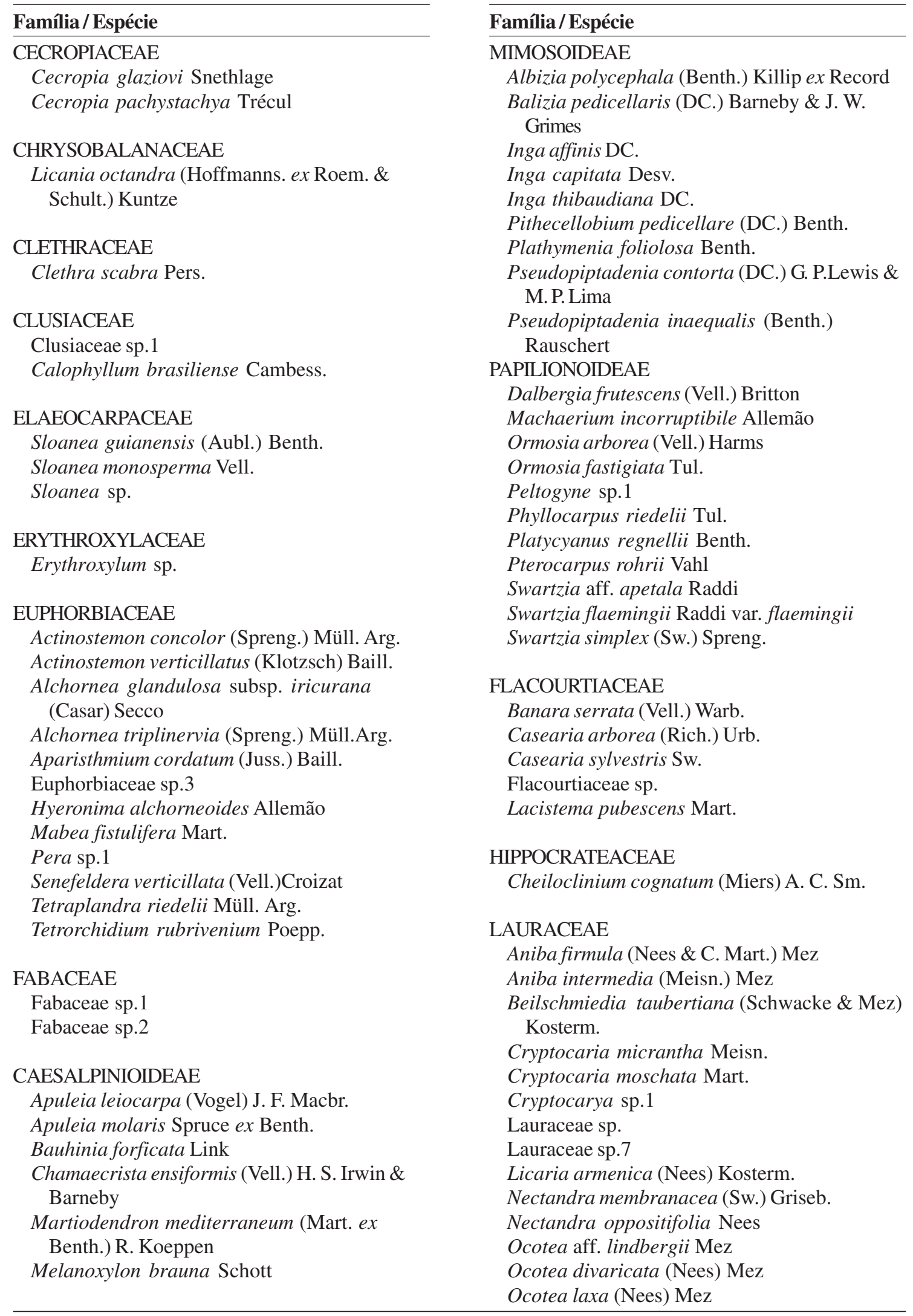




\section{Família / Espécie \\ Ocotea martiana $\mathrm{Mez}$ \\ Ocotea spectabilis (Meisn.) Mez \\ Urbanodendron bahiense (Meisn.) J. G. Rohwer}

\section{LECYTHIDACEAE}

Cariniana estrellensis (Raddi) Kuntze

Cariniana legalis (Mart.) Kuntze

Lecythidaceae sp.1

Lecythis lanceolata Poir.

\section{MELASTOMATACEAE}

Miconia cinnamomifolia (DC.) Naudin

Miconia lepidota Schrank \& Mart. ex DC.

Tibouchina estrellensis (Raddi) Cogn.

Tibouchina scrobiculata Cogn.

\section{MELIACEAE}

Cabralea canjerana (Vell.) Mart. subsp. canjerana

Guarea guidonia (L.) Sleumer

Meliaceae sp.

Trichilia casaretti C. DC.

Trichilia lepidota subsp. schumanniana (Harms) T. D. Penn.

Trichilia pallida $\mathrm{Sw}$.

\section{MONIMIACEAE}

Mollinedia cf. salicifolia Perkins

Monimiaceae sp.2

Siparuna guianensis Aubl.

Siparuna reginae (Tul.) A.DC.

\section{MORACEAE}

Brosimum guianense (Aubl.) Huber Ficus gomelleira Kunth \& C. D. Bouché

Helicostylis tomentosa (Poepp. \& Endl.) Rusby

Moraceae sp.1

Naucleopsis oblongifolia (Kuhlm.) Carauta

Pseudolmedia cf. laevis (Ruiz \& Pav.) J.F. Macbr.

Pseudolmedia hirtula Kuhlm.

Sorocea guilleminiana Gaudich.

\section{MYRISTICACEAE}

Virola gardneri (A. DC.) Warb.

Virola oleifera (Schott) A. C. Sm.

\section{MYRSINACEAE}

Ardisia aff. martiana Miq.

\section{MYRTACEAE}

Eugenia sp.
Família / Espécie

Eugenia supraaxillaris Spring

Myrcia cf. hirtiflora DC.

Myrcia fallax (Rich.) DC.

Myrcia racemosa (O. Berg) Kiaersk.

Myrcia rostrata DC.

Myrtaceae sp.

\section{NYCTAGINACEAE}

Guapira nitida (Mart. ex J.A.Schmidt) Lundell Guapira opposita (Vell.) Reitz

Guapira sp.1

QUIINACEAE

Quiina glazovii Engl.

\section{ROSACEAE}

Prunus brasiliensis (Cham. \& Schltdl.) Dietrich

\section{RUBIACEAE}

Amaioua intermedia Mart.

Bathysa mendoncaei K.Schum.

Bathysa stipulata (Vell.) C. Presl.

Faramea multiflora A. Rich. ex DC.

Psychotria sp.1

Randia armata (Sw.) DC.

Simira viridiflora (Allemão \& Saldanha)

Steyerm.

\section{RUTACEAE}

Hortia arborea Engl.

\section{SAPINDACEAE}

Cupania furfuracea Radlk.

Cupania oblongifolia Mart.

Cupania racemosa (Vell.) Radlk.

Cupania sp.1

Matayba guianensis Aubl.

Matayba sp.1

SAPOTACEAE

Chrysophyllum flexuosum Mart.

Ecclinusa ramiflora Mart.

Micropholis crassipedicellata (Mart. \& Eichler ex Miq.) Pierre

Pouteria cf. reticulata (Engl.) Eyma

Pouteria guianensis Aubl.

Pradosia kuhlmannii Toledo

SIMAROUBACEAE

Simarouba amara Aubl.

\section{STERCULIACEAE}

Sterculia chicha A.St.-Hil. ex Turpin 


\author{
Família / Espécie \\ SYMPLOCACEAE \\ Symplocos variabilis Mart. \\ VERBENACEAE \\ Cytharexylum myrianthum Cham.
}

A literatura sobre florestas de baixada, sejam elas aluviais ou sobre morrotes, é insuficiente para o conhecimento de sua flora e estrutura, e as UCs representam importantes fontes de estudo para a compreensão destas florestas, tanto no âmbito das comunidades como no de populações, sobretudo para espécies de distribuição restrita, tanto em amplitude geográfica como em especificidade ambiental.

Pessoa (2003), objetivando investigar o efeito da fragmentação e do isolamento de habitats sobre a estrutura e diversidade dos elementos arbóreos, inventariou três fragmentos de diferentes formas e dimensões na Rebio, dos oito ocorrentes sobre pequenos morrotes, tendo como critério de inclusão DAP $\geq 5 \mathrm{~cm}$. Foram referenciados 1.771 indivíduos de 207 espécies, onde Senefeldera verticillata corresponde à espécie com maior VI nos três fragmentos analisados, decorrente dos elevados valores de densidade da espécie nas diferentes áreas amostrais. Os índices de diversidade ( $\mathrm{H}^{\prime}$ ) obtidos correspondem a 3,02 nats/ind. (fragmento com 1,35 ha), 3,90 nats/ ind. (fragmento com 6,65 ha) e 3,65 nats/ind. (fragmento com 9,34 ha) enquanto os valores de equabilidade $(\mathrm{J})$ correspondem a $0,73,0,83$ e 0,73 , respectivamente. Interessante destacar que os valores encontrados pela autora podem ser explicados, inicialmente, pelo critério distinto de inclusão, que, por sua vez, aumenta a coleta de indivíduos recrutantes, o que acaba por elevar os valores de densidade de determinadas espécies, sem contudo, aumentar a riqueza de táxons nas amostras (o que pode ser corroborado pelos valores encontrados para equabilidade). Outro fator de influência, a ser ponderado, refere-se à localização dos sítios tratados: mais a noroeste da Rebio, mais próximos à área da Represa

\author{
Família / Espécie \\ VIOLACEAE \\ Rinorea guianensis Aubl. \\ VOCHYSIACEAE \\ Vochysia $\mathrm{sp} .1$
}

de Juturnaíba e, possivelmente, mais sujeitos à interferência na composição e caracterização dos solos, visto que, a porção norte de toda a Rebio é margeada por solos turfosos. O tamanho do fragmento, para efeito de comparação, poderia ser igualmente considerado, porém, os dados disponíveis, impossibilitam uma adequada inferência sobre a influência da forma e tamanho entre os fragmentos estudados por Pessoa (2003) e este estudo.

Analisando o estrato arbóreo de uma toposseqüência alterada, de Floresta Ombrófila Densa submontana, próxima à Rebio, com critério de inclusão de DAP $\geq 3,18$, Borém \& Oliveira-Filho (2002) encontraram 129 espécies e o valor do índice de diversidade (H') igual a 4,137 nats/ind. Os resultados obtidos pelos autores, ao inventariarem cotas altitudinais que denominaram terços: inferior, médio e superior, expressam que o critério de inclusão influi fortemente na caracterização da vegetação, quando comparados aos resultados neste estudo obtidos, pois como afirmam: "Em todos os ambientes estudados observa-se que dentre as espécies mais importantes (maior VI) muitas apresentam como estratégia de ocupação do ambiente muitos indivíduos de porte relativamente reduzido, enquanto a minoria apresenta poucos indivíduos que podem alcançar grandes dimensões." Ou seja, as espécies amostradas são, em sua maioria, espécies pioneiras ou secundárias iniciais, cujos diâmetros, nas diferentes topossequiências analisadas, distribuem-se semelhantemente e concentram a maior densidade de seus indivíduos entre as classes 7,5 e $12,5 \mathrm{~cm}$, especialmente no terço superior, onde as árvores de pequeno diâmetro são mais freqüentes. Conseqüentemente, diferem dos 
resultados obtidos quando avaliadas as espécies de dossel, uma vez que os autores coletaram com maior frequiência elementos mais típicos à sub-mata do que propriamente recrutantes de espécies de dossel.

As famílias que reúnem $73,9 \%$ dos indivíduos presentes no dossel (fig. 2) do trecho analisado são: Euphorbiaceae $(12,4 \%)$, Fabaceae (6,7\%), Moraceae (6,2\%), Lauraceae $(5,7 \%)$, Melastomataceae $(5,7 \%)$, Myrtaceae $(5,7 \%)$, Monimiaceae $(5,3 \%)$, Clethraceae $(4,6 \%)$, Flacourtiaceae $(4,5 \%)$, Annonaceae $(4,5 \%)$, Rubiaceae $(3,4 \%)$, Meliaceae $(3,1 \%)$, Sapindaceae $(3,1 \%)$ e Myristicaceae $(3,0 \%)$. Estes resultados refletem mais uma conjunção entre a riqueza de táxons para cada família e seus respectivos indivíduos, do que, propriamente, elevadas densidades populacionais para determinados táxons, como podem exemplificar: Euphorbiaceae (32 inds:12 spp.), Fabaceae (62:25) e Lauraceae (33:19). As espécies com maiores densidades na área são: Siparuna reginae, Clethra scabra, Senefeldera verticillata, Mabea piriri, Tibouchina estrellensis e Casearia arborea, algumas caracteristicamente espécies pioneiras em Florestas Ombrófilas Densas Atlânticas.

Ao serem comparados os valores de densidade de dossel aos de sub-mata, verificase que grande número de indivíduos, constituem elementos de dossel em recrutamento como: Clethra scabra,

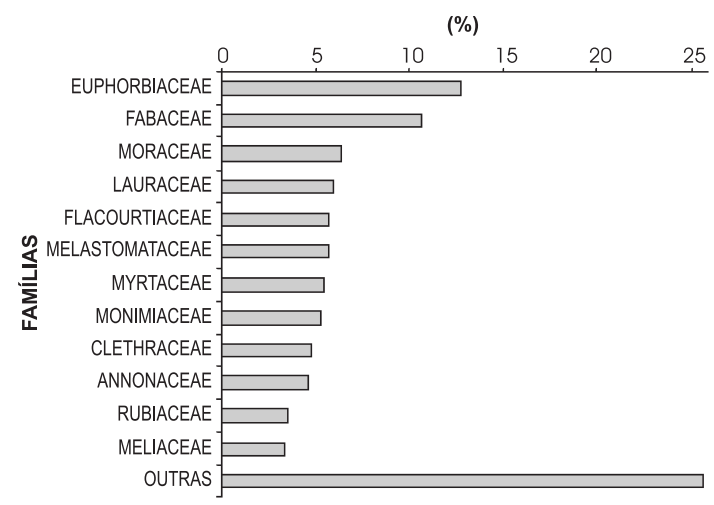

Figura 2 - Distribuição percentual de abundância por famílias, na área de floresta sobre morrote.
Senefeldera verticillata, Lacistema pubescens, Siparuna reginae.

Guapira opposita, Alchornea triplinervia e Euterpe edulis, presentes no dossel com densidades entre 2 e 1 indivíduos por hectare, são freqüentemente registradas em inventários no Rio de Janeiro, sobretudo em áreas de baixada e sopé de serra, conforme Siqueira (1994), quando as destaca entre as 10 espécies presentes em cerca de $50 \%$ dos levantamentos realizados em áreas de Floresta Ombrófila Densa Atlântica em todo o território brasileiro.

Ao trabalhar em área de Floresta Ombrófila Densa Atlântica em Ubatuba, São Paulo, em cotas altitudinais que variaram entre 20 e 190 ms.m, e adotando como critério de inclusão árvores com DAPs $\geq 10 \mathrm{~cm}$, Silva (1980) relaciona, igualmente, Euphorbiaceae, Arecaceae, Lauraceae e Fabaceae entre as famílias mais ricas, com Rubiaceae formando o grupo mais numeroso e Myrtaceae a menos numerosa, dentre as seis famílias mais ricas. Os resultados de Ubatuba são, ainda hoje, dos estudos realizados no estado de São Paulo, os que mais se aproximam dos resultados encontrados para áreas de baixada no Rio de Janeiro.

Em seu estudo realizado em área de Floresta Ombrófila submontana Atlântica na Juréia, São Paulo, Mantovani (1993) destacou entre as famílias com maiores números de indivíduos no dossel, ou componente dominante (DAPs $\geq 9,55 \mathrm{~cm})$ : Myrtaceae, Arecaceae, Sapotaceae, Bombacaceae, Lauraceae e Euphorbiaceae. Contudo, ao serem somadas as três subfamílias de Fabaceae, tratadas pelo autor como três famílias independentes, este táxon passa a apresentar grande relevância neste parâmetro. Embora as famílias relacionadas sejam assemelhadas às encontradas na Rebio, contudo diferem em aguns aspectos. Inicialmente cabe ressaltar que a área de estudo da Juréia é melhor conservada do que a da Rebio, o que por si só já agrega elementos tais como as densidades elevadas de espécies das famílias Myrtaceae, Arecaceae (esta, em grande parte, pela presença de Euterpe edulis, espécie mais rara 
nas amostragens da Rebio) e Sapotaceae mais próximas à condição de secundárias tardias. Na Rebio, as três famílias, a título de exemplificação, com maior número de indivíduos: Euphorbiaceae (Senefeldera verticillata e Mabea piriri), Fabaceae (Pseudopiptadenia inaequalis, Apuleia leiocarpa entre outras) e Moraceae (Brosimum guianense, Sorocea guilleminiana entre outras) são mais expressivas pelas densidades das espécies a elas subordinadas, como também, mais características a condições de vegetação alterada, as quais se expressam no ambiente como pioneiras ou secundárias iniciais.

Quanto à riqueza (fig. 3), 14 famílias concentram $75 \%$ das espécies ocorrentes no dossel, entre elas: Fabaceae $(14,4 \%)$, Lauraceae $(11,0 \%)$, Euphorbiaceae $(7,0 \%)$, Moraceae $(6,0 \%)$, Myrtaceae $(5,2 \%)$, Annonaceae $(5,2 \%)$, Bignoniaceae $(4,6 \%)$, Sapotaceae $(3,4 \%)$, Meliaceae $(3,4 \%)$, Rubiaceae $(3,4 \%)$, Flacourtiaceae $(2,8 \%)$, Melastomataceae $(2,3 \%)$, Monimiaceae $(2,3 \%)$, Lecythidaceae $(2,3 \%)$ e Nyctaginaceae $(1,7 \%)$. Este parâmetro pouco difere dos demais relacionados por diferentes autores para áreas de baixada como Guedes (1998), Borém \& OliveiraFilho (2002), Pessoa (2003) e Guedes-Bruni (2006). O que ocorre são pequenas diferenças relativas à ocorrência de espécies, mais competitivas para estabelecimento, sob uma ou outra condição, característica a cada uma das áreas de estudo e que acabam por interferir, na maior ou menor riqueza dos grupos taxonômicos.

Assim, ao considerarmos os valores de importância dos táxons ocorrentes na floresta de morrote (tab.2), são destacáveis: Senefeldera verticillata, Siparuna reginae, Mabea piriri, Casearia sylvestris, Clethra scabra, Tibouchina scrobiculata, Pseudopiptadenia inaequalis, Guapira opposita, Apuleia leiocarpa e Brosimum guianense, várias delas características de etapas iniciais da sucessão florestal.

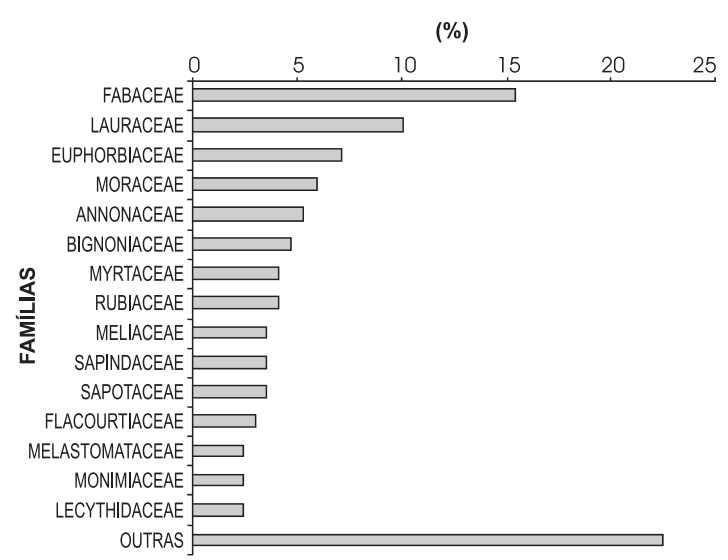

Figura 3 - Distribuição percentual da riqueza de espécies por famílias, na área de floresta sobre morrote.

Quando considerada a estrutura de abundância da vegetação, tanto para a densidade como para a área basal, foram obtidos valores pouco superiores aos de trechos inventariados sobre pequenas elevações, típicas das baixadas do Rio de Janeiro, como em Guedes-Bruni (1998), onde foi adotada a mesma metodologia, destacadamente, o mesmo critério de inclusão. Nesta área de estudo, a densidade foi de 580 ind./ha com área basal de 26,85 $\mathrm{m}^{2} /$ ha. enquanto para área de floresta aluvial, nesta mesma Rebio, Guedes-Bruni et al. (2006), referenciam 486 ind./ha e área basal de $23,77 \mathrm{~m}^{2} / \mathrm{ha}$. As diferenças aqui observadas podem refletir, primeiramente, a variação de solos, que se dá desde as porções mais baixas até às mais elevadas do morrote. Além disto, também há penetração de luz no interior das florestas nas áreas declivosas, que permitiria o maior desenvolvimento na sub-mata e o conseqüente acréscimo de biomassa, além do alagamento, permanente ou temporário, de porções dos terrenos aluviais, decorrentes das cheias dos rios.

Em estudo realizado em uma topossequiência, Borém \& Oliveira-Filho (2002) destacam nos terço inferior, médio e superior densidades e áreas basais de 147 ind./ha e $15,13 \mathrm{~m}^{2} / \mathrm{ha}, 177 \mathrm{ind} . / \mathrm{ha}$ e $20,81 \mathrm{~m}^{2} / \mathrm{ha}$ e 255 ind./ha e 33,34 $\mathrm{m}^{2} / \mathrm{ha}$, respectivamente. Estes mesmos autores indicam ainda um aumento nos números de espécies e nos subseqüentes 
valores de H' das toposseqüências, da inferior para a superior, que acabam por retratar um gradiente de perturbação nas mesmas. No trecho analisado na Rebio, observa-se a ocorrência de um número superior de indivíduos de maior porte nas porções basais e medianas do morrote, enquanto que na cumeeira, talvez em decorrência dos morrotes serem tênuemente aplainados, observa-se um maior número de indivíduos, mais característicamente arvoretas do que árvores. Muitas destas arvoretas são espécies secundárias tardias que sombreiam a sub-mata densamente ocupada por elementos de Astrocaryum aculeatissimum.

À semelhança do observado por Borém \& Oliveira Filho (2002), no que concerne à distribuição diamétrica, ao longo do gradiente das topossequências, possivelmente, o histórico recente da região da bacia do rio São João, possa explicar, parcialmente este cenário de dados. Se a vegetação dos arredores, que circundam estes morrotes, são áreas de solo seco, muito provavelmente, foi utilizada: primeiramente para extração de madeira nobre, há 30 anos, conforme relato dos moradores locais (Christo et al 2006), num segundo momento para extração de lenha, destinada ao abastecimento de fornos de olarias e panificadoras (Guedes 1988) e numa última etapa de uso, para implantação de pequenas lavouras ou pastagem. Se, contudo, as áreas circundantes aos morrotes são inundáveis, muitas das espécies que ocorrem nas áreas aluviais se dispersam até as cotas medianas dos morrotes e por esta razão não só a natureza do solo impõe dificuldade de seu uso, como também, propicia às populações vegetais manterem seu curso natural de crescimento e estabelecimento na área. A ocorrência, por sua vez, de espécies (mais encontradiças nos limites entre as florestas submontanas e montanas) reconhecidas culturalmente como apropriadas à construção, ao uso medicinal e demais benefícios, nas partes superiores dos morrotes, propicia a exploração seletiva, por parte das comunidades rurais, o que justifica a abertura de clareiras. Dentre elas podem ser citadas: Apuleia leiocarpa (garapa), Virola gardnerii (bicuíba - verdadeira), $V$. oleifera (bicuíba), Brosimum guianense (muirapinima ou muirapinima-preta), Sorocea guilleminiana (espinheira-santa) e Sparattosperma leucanthum (cinco-folhas ou cinco-chagas). Neste processo de exploração, com abertura de pequenas a médias clareiras, nas cotas superiores dos morrotes, decorre a ocupação dos espaços abertos por espécies heliófilas, característicamente pioneiras ou secundárias iniciais, em forma de arvoretas e cujo elevado número de indivíduos, muitas das vezes estiolados, com pequenos diâmetros, podem justificar os resultados encontrados em ambos os estudos.

$\mathrm{Na}$ estrutura de tamanho, $74 \%$ dos indivíduos encontram-se distribuídos com diâmetros entre 10 e $31 \mathrm{~cm}$ (fig. 4), com diâmetro médio equivalente a $21,4 \mathrm{~cm}$, onde exemplares com maiores taxas de crescimento

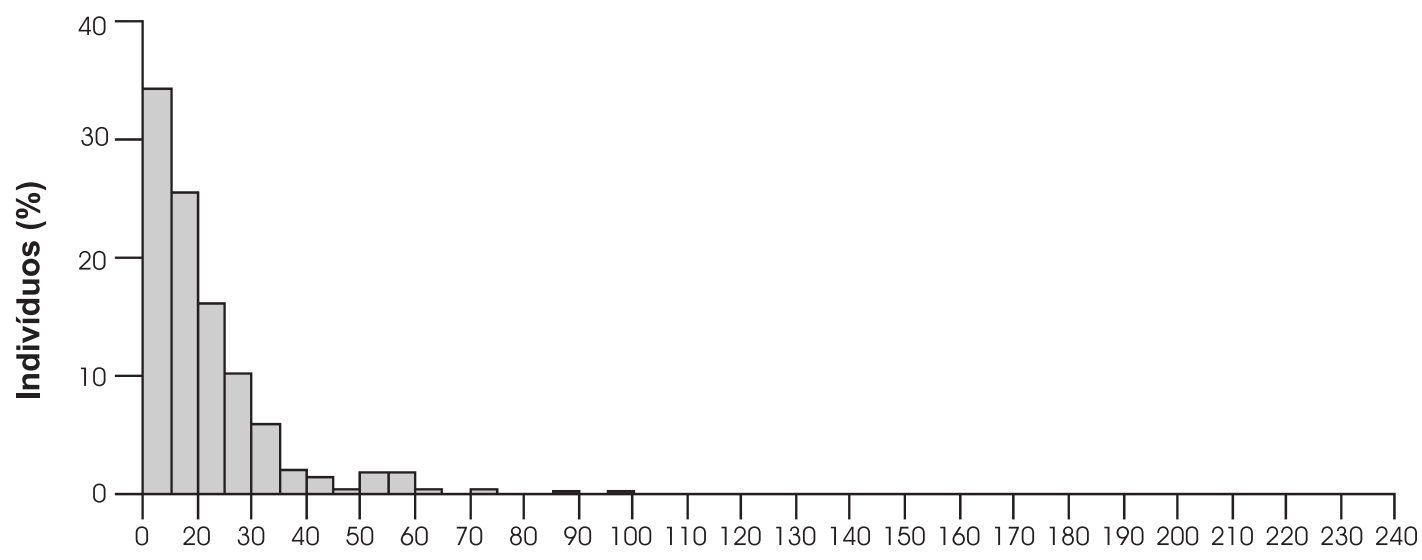

Classes de diâmetro $(\mathrm{cm})$

Figura 4 - Distribuição de indivíduos, segundo as classes de diâmetro, na área de floresta sobre morrote (cm). 
secundário ocorriam acima do dossel, como emergentes, exemplificados por: Pouteria cf. reticulata, cujo diâmetro de $0,89 \mathrm{~m}$ foi o maior obtido na amostragem, além de Vernonia discolor $(0,74 \mathrm{~m})$, Cariniana legalis $(0,73 \mathrm{~m})$, Cariniana estrellensis $(0,65 \mathrm{~m})$ e Guarea guidonia $(0,64 \mathrm{~m})$.

A altura média da floresta foi de $16 \mathrm{~m}$, concentrando $77 \%$ dos indivíduos na faixa entre 10 e $25 \mathrm{~m}$ de altura (fig. 5). Ao considerarmos as alturas atingidas pelos indivíduos emergentes, cuja altura máxima registrada foi de $32 \mathrm{~m}$, por um indíviduo de Guarea guidonia, assinalamos: Pouteria cf. reticulata $(30 \mathrm{~m})$, Apuleia leiocarpa $(30 \mathrm{~m})$ e Cariniana legalis (30 m), cujas alturas são superiores às verificadas na mata aluvial por Guedes-Bruni et al. (2006).

Neste levantamento, ressaltam-se as espécies: Tabernamontana australis, Cecropia glazioui, Cecropia pachystachya, Clethra scabra, Mabea piriri, Pera sp., Dalbergia frutescens, Casearia sylvestris, Miconia cinnamomifolia, Miconia lepidota, Tibouchina estrellensis, Ardisia aff. martiana, Myrcia fallax, Myrcia rostrata, Prunus brasiliensis, Simarouba amara e Cytharexylum myrianthum, como indicadoras de estádios iniciais da sucessão florestal na Floresta Ombrófila Densa Atlântica.

Ainda que mais intensamente estudada na última década, como destacado por Guedes-Bruni et al. (2006), abordagens que contemplem os diferentes fatores atuantes no recrutamento e no estabelecimento de espécies; identificação de espécie ou de espécies-chave para recuperação de áreas, estratégias reprodutivas e de propagação constituem acentuados vazios científicos. Tais abordagens, por sua vez, não podem prescindir do concurso de especialidades distintas que possam, de forma integradora, confluir para a efetivação de proposições à conservação de espécies, sobretudo, as endêmicas e com populações reduzidas.

A riqueza de espécies expressa enormes variações geográficas em diferentes escalas

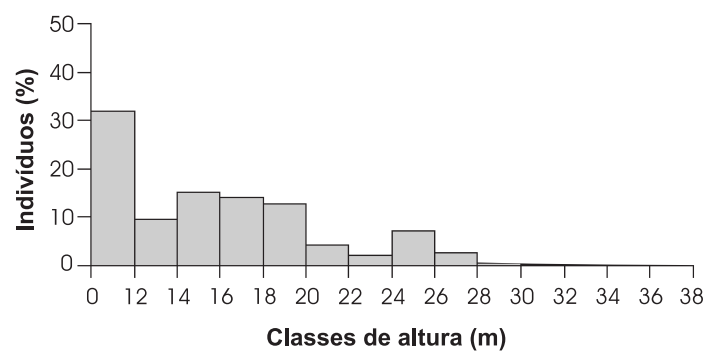

Figura 5 - Distribuição de indivíduos, segundo classes de altura, na área de floresta sobre morrote $(\mathrm{m})$.

e muitos são os processos que, potencialmente, podem interferir no grau de riqueza de espécies (Ricklefs \& Schluter 1993), tais como: fatores físicos (clima e suprimento de energia, p.ex.), fatores históricos (taxas de especiação e dispersão) e interações bióticas (predação e competição). Cornell \& Karlson (1997), por sua vez, lembram que existem limites para a riqueza de espécies, não só em função da restrição de recursos disponíveis, como também por fatores físicos. Ao avaliarem os efeitos da competição na estruturação de comunidades locais, identificam como um campo estimulante a observação da relação entre riquezas locais e regionais.

Guedes-Bruni (1998), valendo-se de métodos de ordenação, observa que a Floresta Ombrófila sobre morrotes, representada por esta amostragem, tem como espécies indicadoras: Lacistema pubescens, Xylopia sericea, Miconnia cinnamomifolia e Guapira opposita, menos por suas peculiaridades biológicas (que poderiam gerar a falsa idéia de tipicidade ou caracterização destas florestas sobre mamelões em estádio de maturidade) e muito mais por seus amplos padrões de distribuição geográfica ao longo da faixa Oriental brasileira, com o concurso de suas características de ocupação e propagação em áreas alteradas. Assim sendo, tais espécies indicadoras reforçam a característica de elevado grau de alteração dos fragmentos da região, ainda que o fragmento selecionado represente um dos mais compatíveis com as características de um fragmento bem conservado. 


\section{Conclusões}

O componente dominante da floresta sobre morrote na Rebio Poço das Antas, quando comparado ao dos demais trabalhos desenvolvidos em áreas de vegetação arbórea na UC, ou nos seus arredores, expressa um diversificado elenco de respostas, que relacionam os resultados aqui obtidos não só à natureza do processo de interferência no ambiente (fogo, extração seletiva, rocio, tipo de lavoura implantada etc.), como também o tempo decorrido da perturbação até às diferentes fases de alteração e reconstituição da estrutura e da composição florística.

A vegetação ocorrente sobre morrote encontra-se, do ponto de vista da observação fisionômica, sob influência de poucos fatores de estresses, pelo menos no que tange à influência hídrica e subseqüentes processos de decomposição de matéria orgânica, excluídos os efeitos decorrentes de fortes ventos ocorrentes com a chegada de massas frias oceânicas, que podem acabar por gerar quedas de árvores e, subseqüentes, formações de clareiras de diferentes tamanhos e formas.

No caso da floresta sobre morrotes, o fator de transformação mais relevante é o corte da lenha para posterior estabelecimento da pecuária. O fogo é um fator acessório, porém mais afeto à manutenção da condição de pastoreio do que, propriamente, à derrubada da floresta.

A riqueza de espécies, na área de estudo, reflete a ação antrópica como deflagradora de interferência em fatores a ela relacionados: como elevadas temperaturas decorrentes dos incêndios freqüentes e ampliação de territórios abertos (pastos), que por sua vez intereferem nos processos: de sucessão de espécies, maior ou menor facilidade de resiliência, maior ou menor facilidade de dispersão de propágulos e intereferência nas interações planta-animal, essenciais aos ciclos biológicos, de cada grupo, imprimindo-lhes, maior ou menor capacidade de competição, estabelecimento e reprodução.

A riqueza de espécies das famílias: Fabaceae (com grande variedade de gêneros), Euphorbiaceae (várias espécies típicas das baixadas fluminenses e de áreas impactadas), Lauraceae, Moraceae (destacadamente Ficus) e Myrtaceae (sobretudo, Eugenia e Myrcia) têm sido referenciadas por vários autores para o componente dominante da Floresta Ombrófila Densa Atlântica.

Na flora inventariada, várias espécies são indicadoras de estádios iniciais da sucessão florestal, somando muitos indivíduos, e coexistindo ao lado de espécies de etapas tardias da sucessão, acaba por ressaltar o caráter alterado da área estudada.

Os resultados aqui expressos reiteram a importância que os fragmentos florestais têm para a conservação da diversidade florística da região centro-norte do Rio de Janeiro e para a qual a Reserva Biológica de Poço das Antas constitui uma importante UC para a realização de estudos sobre processos de regeneração natural, experimentos para a restauração ecológica dos reduzidos remanescentes dispersos pela região, de modo a contribuir efetivamente, para a reconstituição da paisagem, desta grande porção territorial do Rio de Janeiro. Região esta caracterizada: por sua circunscrição a uma importante bacia hidro-gráfica; por atividade agro-pecuária decadente e por, mais ao norte, em Campos dos Goytacases, a indústria canavieira, desaquecida, vir promovendo a migração de agricultores sem terra para os arredores da Rebio, aumentando, por conseguinte, a pressão sobre os poucos remanescentes florestais.

\section{Agradecimentos}

Ao Jardim Botânico do Rio de Janeiro pelo apoio ao projeto de doutorado; ao $\mathrm{CNPq}$ pela bolsa concedida, durante parte do período do curso, à primeira autora; ao Depto. de Ecologia da Universidade de São Paulo USP; à The John D. and Catherine T. MacArthur Foundation e à Cia. Petrobrás financiadoras do Programa Mata Atlântica (PMA) e aos colegas que nos auxiliaram na obtenção de dados de campo, especialmente: Gustavo Martinelli, Solange de V. A. Pessoa, Tânia S. Pereira, Lana da S. Sylvestre, Claudia F. Barros, Catia Callado e ao auxiliar de campo 
Jorge Caruso Gomes; e, finalmente, aos taxonomistas que conferiram acurácia às identificações: Alexandre Quinet, Angela S.da Fonseca Vaz, Ariane L. Peixoto, Arline de Souza, Ary Gomes da Silva, Claudia M. Vieira, Elsie F. Guimarães, Genise V. Somner, Jorge Pedro Carauta, José Fernando A. Baumgratz, Nilda Marquete F. da Silva e, especialmente, Haroldo C. de Lima e Dra. Graziela M. Barroso, esta última in memoriam.

\section{REFERÊNCIAS BIBLIOGRÁFICAS}

Azevedo, F. 1996. A Cultura Brasileira. Rio de Janeiro: Ed.UFRJ, Brasília: UnB. Pp. 83-124.

Borém, R. A. T. \& Oliveira-Filho, A. T. 2002. Fitossociologia do estrato arbóreo em uma toposseqüência alterada de mata Atlântica, no município de Silva Jardim - RJ. Revista Árvore 26(6): 727-742.

Cornell, H. V. \& Karlson, R. 1997. Local and regional processes as controls of species richness. In: Tilman, D. \& Kareiva, P. (eds.). Spatial Ecology: the role of space in population dynamics and interspecific interactions. Pp. 250-268.

Cronquist, A. 1988. The evolution and classification of flowering plants. $2^{\text {nd }}$ ed. New York Botanical Garden, New York, 555p.

Fundação SOS Mata Atlântica/INPE 2002. Atlas dos Remanescentes Florestais da Mata Atlântica período 1995 - 2000 Relatório parcial. Estado do Rio de Janeiro [on line] Disponível na internet via http:// www.sosmatatlantica.org.br. Arquivo capturado em 20 de junho de 2002.

Golfari. L. \& Moosmayer, H. 1980. Manual de reflorestamento do estado do Rio de Janeiro. Rio de Janeiro. Banco de Desenvolvimento do Estado do Rio de Janeiro, Secretaria de Planejamento e Coordenação Geral.

Guedes, R. R. 1988. Composição florística e estrutura de um trecho de mata perturbada de baixada no município de Magé, Rio de Janeiro. Arquivos do Jardim Botânico do Rio de Janeiro 39: 155-200.
Guedes-Bruni, R. R. 1998. Composição, estrutura e similaridade florística de dossel em seis unidades de Mata Atlântica no Rio de Janeiro. Tese de Doutorado. Universidade de São Paulo, São Paulo, 347p. ; Silva Neto, S. J.; Morim, M. P. \& Mantovani, W. 2006. Composição florística e estrutura de trecho de Floresta Ombrófila Densa Atlântica aluvial na Reserva Biológica de Poço das Antas, Silva Jardim, Rio de Janeiro, Brasil. Rodriguesia 57(3): 413-428.

IBGE. 1977. Geografia do Brasil: Região Sudeste. vol.3. Rio de Janeiro. Superintendência de Estudos Geográficos e Sócio-econômicos. Departamento de Geografia. Fundação Instituto Brasileiro de Geografia e Estatística - IBGE. Diretoria Técnica. Diretoria de Divulgação, 667p.

Lamego, A. R. 1940. O homem e o brejo. Série Os Setores da Evolução Fluminense. vol. I. IBGE, Rio de Janeiro.

1946. O homem e a restinga. Série

Os Setores da Evolução Fluminense. vol II. IBGE, Rio de Janeiro. . 1948. O homem e a Guanabara. Série Os Setores da Evolução Fluminense. vol. III. IBGE, Rio de Janeiro.

Lima, H. C. 2000. Leguminosas arbóreas da Mata Atlântica. (Tese de doutorado). Universidade Federal do Rio de Janeiro, Rio de Janeiro, 141p.

Lima, H. C.; Pessoa, S. V. A.; Guedes-Bruni, R. R.; Moraes, L. F. D.; Granzotto, S. V.; Iwamoto, S. \& Di Ciero, J. 2006. Caracterização fisionômico-florística e mapeamento da vegetação da Reserva Biológica de Poço das Antas, Silva Jardim, Rio de Janeiro, Brasil. Rodriguésia 57 (3): 369-389.

Kurtz, B. C. \& Araújo, D. S. D. 2000. Composição florística e estrutura do componente arbóreo de um trecho de Mata Atlântica na Estação Ecológica Estadual do Paraíso, Cachoeiras de Macacu, Rio de Janeiro, Brasil. Rodriguésia 51(78/79): 69-111. 
Magurran, A. E. 1988. Ecological Diversity and its Measurement. Princeton University Press, Princeton. Pp. 81-99.

Mantovani, W. 1993. Estrutura e dinâmica da Floresta Atlântica na Juréia, Iguape, SP. Tese de Livre Docência. Universidade de São Paulo, São Paulo, 126p.

Melo, M. M. R. F.; Oliveira, R. J.; Mamede, M. C. H.; Rossi, L. \& Cordeiro, I. 1998. Fitossociologia de um trecho de Mata Atlântica de Planície na Estação Ecológica de Juréia-Itatins, SP, Brasil. In: IV Simpósio de Ecossistemas Brasileiros - Promoção da Academia de Ciências do Estado de São Paulo, 1998, Águas de Lindóia. Anais do IV Simpósio de Ecossistemas Brasileiros. Vol. 2. ACIESP, São Paulo. Pp. 49-56.

Moreno, M. R.; Nascimento, M. T. \& Kurtz, B. 2003. Estrutura e composição florística do estrato arbóreo em duas zonas altitudinais de mata atlântica de encosta da região do Imbé, RJ. Acta Botânica Brasílica 17(3): 325-486.

Oliveira, R. R.; Zaú, A. S.; Lima, D. F.; Silva, M. B. R.; Vianna, M. C.; Sodré, D. O. \& Sampaio, P. D. 1995. Significado ecológico da orientação de encostas no maciço da Tijuca, Rio de janeiro. Oecologia brasiliensis 1: 523-541.

Pessoa, S. V. A. 2003. Aspectos da fragmentação em remanescentes florestais da planície costeira do estado do Rio de Janeiro. Rio de Janeiro. Dissertação de Mestrado. Universidade Federal Rural do Rio de Janeiro, Rio de Janeiro, 111p.

Pielou, E. C. 1984. The Interpretation of Ecological Data. A primer on classifIcation and ordination. Ed. John Wiley \& Sons, Inc., New York, 263p.

Polhill, R. M.; Raven, P. H. \& Stirton, C. H. 1981. Evolution and systematics of the Fabaceae. In: Polhill, R. M. \& Raven, P.
H. (eds). Advances in Legume Systematics, London. Royal Botanic Gardens, Kew 1: 1-26.

Ricklefs, R. E. \& Schluter, D. 1993. Species diversity in Ecological Communities: historical and geographical perspectives. The University of Chicago Press, Chicago, 365p.

Rodrigues, H. C. 1996. Composição florística e fitossociológica de um trecho de Mata Atlântica na Reserva Biológica do Tinguá, Nova Iguaçu, Rio de Janeiro. Dissertação de Mestrado. Universidade Federal do Rio de Janeiro, Rio de Janeiro, 77p.

Shepherd, G. I. 1995. FITOPAC 1. Manual do Usuário. Campinas. Departamento de Botânica. Universidade Estadual de Campinas.

Silva, A. F. 1980. Composição florística e estrutura de um trecho de Mata Atlântica de encosta no município de Ubatuba, São Paulo. Dissertação de Mestrado. Universidade Estadual de Campinas, Campinas, 80p.

Silva, G. C. \& Nascimento, M. T. 2001. Fitossociologia de um remanescente de mata sobre tabuleiros no norte do estado do Rio de Janeiro (Mata do Carvão). Revista Brasileira de Botânica 24(1): 51-62.

Siqueira, M. F. de. 1994. Análise florística e ordenação de espécies arbóreas da Mata Atlântica através de dados binários. Dissertação de Mestrado. Universidade Estadual de Campinas, Campinas, 143p.

Sneath, P. H. A. \& Sokal, R. R. 1973. Numerical Taxonomy. W.H. Freeman \& Co., San Francisco, 513p.

Veloso, H. P.; Rangel-Filho, A. L. R. \& Lima, J. C. A. 1991. Classificação da vegetação brasileira adaptada a um sistema universal. IBGE, Rio de Janeiro, 124p. 